\title{
Promovendo a Educação Ambiental através da compostagem domiciliar
}

\section{Promoting Environmental Education through household composting}

\section{Promoviendo la Educación Ambiental a través del compostaje domiciliar}

\begin{abstract}
Claucia Brentano ${ }^{1}$
Tamires Lopes Podewils ${ }^{2}$

Alana das Neves Pedruzzi ${ }^{3}$

Resumo

Este artigo apresenta o relato das ações do projeto Promovendo a Educação Ambiental (EA) através da compostagem domiciliar, que aconteceu no bairro Aurora, no município de Campo Bom/RS. Partimos do questionamento: É possível desenvolver compreensões de EA Crítica a partir do uso de composteiras? Como objetivos: 1 - Resgatar um modelo e técnica de compostagem domiciliar; 2- Engajar os moradores visando a consciência crítica acerca desse problema; 3- Avaliar o conhecimento da comunidade sobre a separação e tratamento de resíduos. Concluímos que a EA Crítica permeou o processo de construção da composteira doméstica, e de conscientização crítica dos envolvidos, enfatizando a simplicidade e eficiência destas no uso cotidiano das famílias, trazendo benefícios para o ambiente e para a qualidade de vida dos envolvidos.
\end{abstract}

Palavras-chave: Educação Ambiental. Compostagem. Resíduos.

\begin{abstract}
This article presents an account of the actions of the Promoting Environmental Education (EA) project through household composting, which took place in the Aurora neighborhood, in the municipality of Campo Bom / RS. We start from the question: Is it possible to develop understandings of critical AI from the use of composites? As objectives: 1 - To rescue a model and technique of household composting; 2 - Engage residents with critical awareness about this problem; 3- Evaluate the community's knowledge about the separation and treatment of waste. We conclude that EA Crítica permeated the process of construction of the domestic composter, and of critical awareness of those involved, emphasizing the simplicity and efficiency of these in the daily use of families, bringing benefits to the environment and the quality of life of those involved.
\end{abstract}

Keywords: Environmental education. Composting. Residue.

\section{Resumen}

Este artículo presenta el relato de las acciones del proyecto Promoviendo la Educación Ambiental (EA) a través del compostaje domiciliar, que tuvo lugar en el barrio Aurora, en el municipio de Campo Bom / RS. Partimos del cuestionamiento: ¿Es posible desarrollar entendimientos de EA Crítica a partir del uso de composteras? Como objetivos: 1 - Rescatar un modelo y técnica de compostaje domiciliar; 2- Enfoque a los habitantes con el objetivo de la conciencia crítica de este problema; 3- Evaluar el conocimiento de la comunidad sobre la separación y el tratamiento de residuos. Concluimos que la EA Crítica permeó el proceso de construcción de la composición doméstica, y de concientización crítica de los involucrados, enfatizando la simplicidad y eficiencia de éstas en el uso cotidiano de las familias, trayendo beneficios para el ambiente y para la calidad de vida de los involucrados.

Palabras clave: Educación ambiental. El compostaje. Residuos.

\footnotetext{
${ }^{1}$ Especialista em Educação Ambiental (FURG). Professora de Ciências e Biologia Colégio Santa Teresinha (Campo Bom/RS). clauciabre@yahoo.com.br.

${ }^{2}$ Mestre e Doutoranda em Educação Ambiental. PPGEA/FURG. Bolsista CNPq - Brasil podewils.t@gmail.com.

${ }^{3}$ Mestre e Doutoranda em Educação Ambiental. PPGEA/FURG. Bolsista CAPES. alanadnp@ gmail.com.
} 


\section{Introdução}

Neste artigo apresentaremos resultados e reflexões referentes a um projeto de ação em Educação Ambiental (EA), que desenvolveu algumas compreensões da Educação Ambiental Crítica a partir da composteira doméstica. Tal proposta de ação foi desenvolvida como atividade obrigatória do curso de Especialização em Educação Ambiental da Universidade Federal do Rio Grande - FURG, sendo concluído no primeiro semestre de 2018. A necessidade de debater tal temática surge pelas práticas cotidianas das autoras deste artigo, bem como pelo reconhecimento de que no Brasil, em torno de 50\% a $60 \%$ dos resíduos domésticos gerados, constituem-se de materiais orgânicos passíveis à compostagem. No entanto, devido à ausência de um sistema de coleta e destinação adequados, estes materiais acabam sendo destinados juntamente a resíduos perigosos, recicláveis e rejeitos para aterros sanitários e lixões, prejudicando o meio natural e a saúde e bem-estar dos seres humanos (MASSUKADO, 2008).

O projeto de ação em Educação Ambiental, que utilizou a composteira como tema gerador, foi desenvolvido no bairro Aurora em Campo Bom/RS. O espaço em que as ações foram realizadas foi o pavilhão da Igreja Católica, onde o Colégio Santa Teresinha realiza mensalmente o "Projeto Solidário". A ação contou com um público de aproximadamente vinte mulheres.

A partir do desenvolvimento de outros projetos de ação no bairro Aurora, foi possível perceber a urgência em discutir pressupostos da Educação Ambiental frente aos visíveis problemas ambientais locais. Dessa forma, foi observado que uma possibilidade seria trabalhar a partir da construção de um composteira, visto que dessa ação poderia derivar a construção de hortas e o cultivo de alimentos pelas famílias. Tal processo poderia ser profícuo à conscientização das pessoas envolvidas quanto à importância do tratamento dos resíduos domésticos, bem como poderia servir também para posterior utilização dos vegetais cultivados na alimentação diária, reduzindo custos para as famílias e propiciando o desenvolvimento de novas formas de relação com a produção alimentícia e uso do solo.

Tanto no desenvolvimento do projeto de ação quanto para, posteriormente, a elaboração deste artigo, partiu-se do pressuposto de que a Educação Ambiental é de suma importância para as comunidades pois permite a formação de cidadãos conscientes que futuramente poderão ser capazes de adotarem estratégias e tomar decisões concernentes à 
sustentabilidade para atuais e futuras gerações, a fim de se comprometerem com o desenvolvimento socioambiental de suas comunidades (FONSECA, 2009).

Portanto, neste artigo utilizou-se como pressupostos teóricos os referenciais da Educação Ambiental Crítica, tendo como fundamento principal os escritos de Carlos Frederico Bernardo Loureiro (2004) que compreende a Educação Ambiental como espaço de diálogo e emancipação dos sujeitos. Também foram utilizadas as contribuições de Moreira Sá (2009) sobre o processo de construção de composteiras, a qual explica que a compostagem, como método de reciclagem do lixo doméstico para a obtenção de adubos orgânicos, é conhecida pelos agricultores desde longa data.

Para o desenvolvimento deste artigo partimos do seguinte questionamento: É possível desenvolver compreensões de uma Educação Ambiental Crítica a partir da composteira como tema gerador? Para tanto, desenvolvemos os seguintes objetivos: 1- Apresentar um relato das ações, onde será descrito sobre cada encontro com a comunidade; 2- Apresentar os pressupostos teóricos, que guiaram nossas ações e análises e; 3- Estabelecer um diálogo entre os pressupostos teóricos e as ações relatadas. A partir destes objetivos observaremos como a Educação Ambiental permeou o espaço da construção da composteira doméstica. Como suporte metodológico utilizamo-nos da pesquisa quantitativa e qualitativa. Foram coletadas informações, a partir de um questionário, para com base nas respostas obtidas, elaborar as práticas das ações. Posteriormente, as ações foram analisadas em diálogo com o referencial teórico da Educação Ambiental Crítica.

Sendo assim, o primeiro tópico deste artigo irá apresentar o percurso metodológico do Projeto de Ação. Neste tópico, intitulado Metodologia, serão apresentados os movimentos de produção do projeto de ação de Educação Ambiental. No segundo momento do artigo será apresentado o Referencial teórico, onde serão desenvolvidas reflexões com base em autores referenciais na área da Educação Ambiental. Na sequência, no tópico de análises de informações, será apresentado o levantamento de dados quantitativos e qualitativos. Ao final do texto, no subtópico intitulado como Considerações, serão reunidos os resultados obtidos através da análise de informações, apontando as principais reflexões desenvolvidas no decorrer do processo de desenvolvimento do Projeto de Ação de Educação Ambiental, bem como na elaboração deste artigo. 


\section{Metodologia}

O Projeto de Ação em Educação Ambiental foi realizado no pavilhão da Igreja Católica do bairro Aurora, no município de Campo Bom/RS, juntamente ao "Projeto Solidário", realizado pelo Colégio Santa Teresinha situado no mesmo município. O projeto atende as famílias de baixa renda, ligadas a comunidade católica. Estima-se um total de aproximadamente vinte famílias atendidas, sendo que este número pode variar. Os encontros acontecem, normalmente, no último sábado de cada mês e integra atividades para as crianças e adultos presentes.

Para o desenvolvimento da Ação em Educação Ambiental foi necessário, em um primeiro momento, aplicar um questionário com a intenção de identificar a percepção ambiental dos envolvidos no projeto de ação. As questões abordadas neste questionário destacaram as diferenças entre resíduos orgânicos e secos, a separação doméstica dos resíduos, a coleta seletiva, a composição da composteira doméstica e seus benefícios e a constituição de uma horta residencial ou comunitária.

A partir dos resultados obtidos no questionário, percebemos a necessidade de um esclarecimento sobre os diferentes tipos de resíduos, a fim de que fossem alargados os conhecimento dos envolvidos no projeto de ação em relação ao conjunto de saberes necessários ao desenvolvimento de uma composteira doméstica ou comunitária. Para isso desenvolvemos, nesta segunda etapa de trabalho, uma palestra somada à demonstração prática sobre as diferenças entre os resíduos sólidos e orgânicos, separação e seus destinos corretos. Na figura a seguir é possível visualizar esta atividade: 
Figura 1: Palestra com as participantes do Projeto

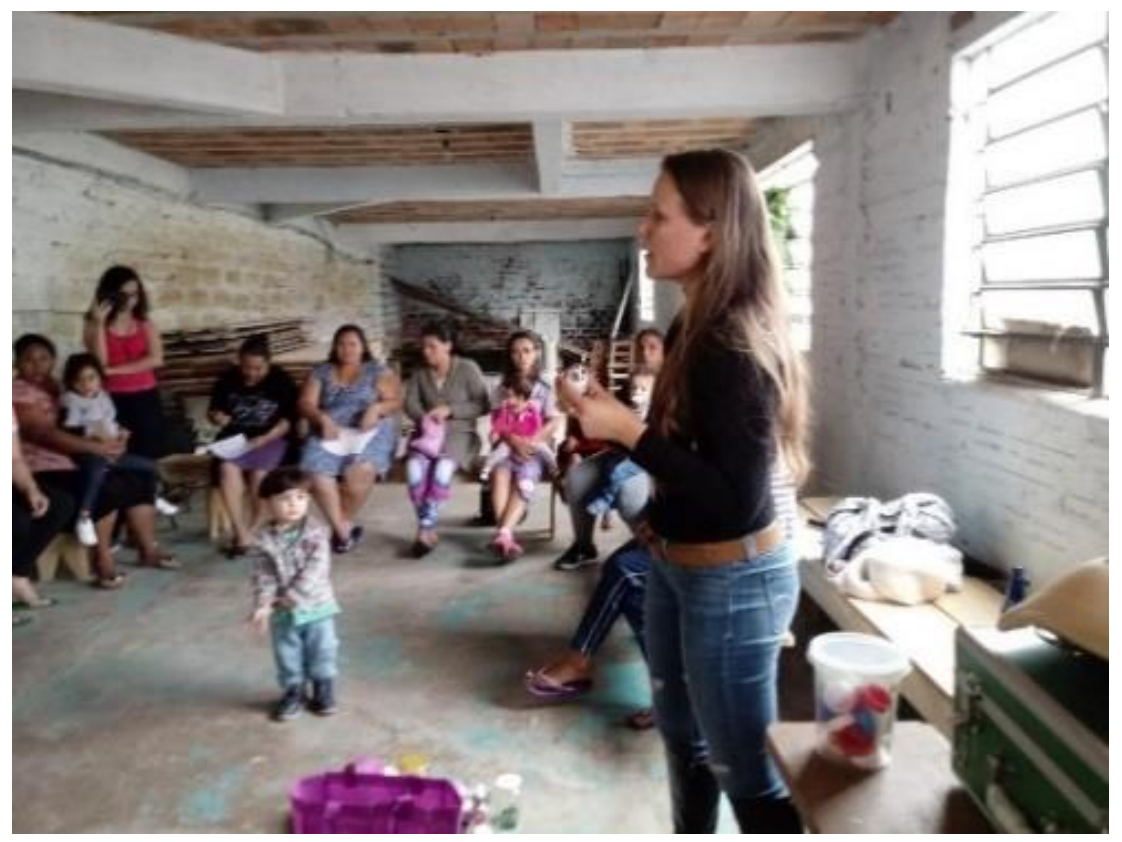

Fonte: Arquivo pessoal da autora.

$\mathrm{Na}$ terceira etapa do projeto, com o intuito de envolver, ainda mais, as famílias nas questões ambientais - diretamente relacionadas com o descarte correto de seus resíduos apresentamos a possibilidade da realização de uma composteira de uso doméstico. A proposta foi construir uma composteira sem custos elevados, fazendo uso de materiais que, possivelmente, seriam descartados ou inutilizados.

Segundo Oliveira, Aquino e Neto (2005) o processo de compostagem apresenta grande potencial de transformação de diversos tipos de resíduos, incorporando ao solo elementos que contribuem amplamente para a melhoria de seus componentes orgânicos. Conforme os autores:

Consequientemente se observa maior eficiência dos adubos minerais aplicados às plantas, proporcionando mais vida ao solo, que apresenta produção por mais tempo e com mais qualidade. Portanto, a redução do uso de fertilizantes químicos na agricultura, a proteção que a matéria orgânica proporciona ao solo contra a degradação e a redução do lixo depositado em aterros sanitários pelo uso dos resíduos orgânicos para compostagem, contribuem para melhoria das condições ambientais e da saúde da população (OLIVEIRA, AQUINO e NETO, 2005, p.1).

A realização do composto, que se dá pela transformação do resíduo orgânico, mostrase muito eficaz para o equilíbrio entre ser humano e o ambiente. Isso se dá, pois o composto é uma fonte rica em nutrientes que contribui para uma terra mais fértil, cooperando de maneira positiva, seu destino não será o aterro sanitário e sim, na produção de uma melhor qualidade 
de vida. Os autores ainda discorrem sobre a interligação entre as vantagens naturais e sociais das práticas de compostagem, segundos estes:

O composto melhora a qualidade do solo e reduz a contaminação e poluição ambiental; estimula o exercício à cidadania pela contribuição na diminuição do lixo destinado aos aterros sanitários; melhora a eficiência dos fertilizantes químicos; economiza espaços físicos em aterros sanitários; recicla os nutrientes e elimina agentes patogênicos dos resíduos domésticos (OLIVEIRA, AQUINO e NETO, 2005, p.5).

Em concordância com os autores, Wangen e Freitas (2010) apontam que "A compostagem doméstica de resíduos sólidos orgânicos consiste numa alternativa viável para a ciclagem deste tipo de resíduo, podendo ser empregada em prefeituras, escolas, casas, condomínios e propriedades rurais (WANGEN e FREITAS, 2010, p. 6)”. Conforme Monteiro (2016):

Além de impulsionar a produção caseira de alimentos, favorecendo a troca e a comercialização das colheitas excedentes ao consumo doméstico, a venda do composto orgânico também pode vir a representar uma fonte alternativa para geração de renda complementar para a família (MONTEIRO, 2016, p.2).

Para tanto, a fim de evidenciar a praticabilidade das compreensões dos autores realizamos uma palestra-oficina (figura 2), com o objetivo de organizar a confecção de composteiras domésticas (figura 3), a partir de materiais que seriam descartados.

Figuras 2 e 3: Oficina com as participantes do Projeto e Composteira pronta

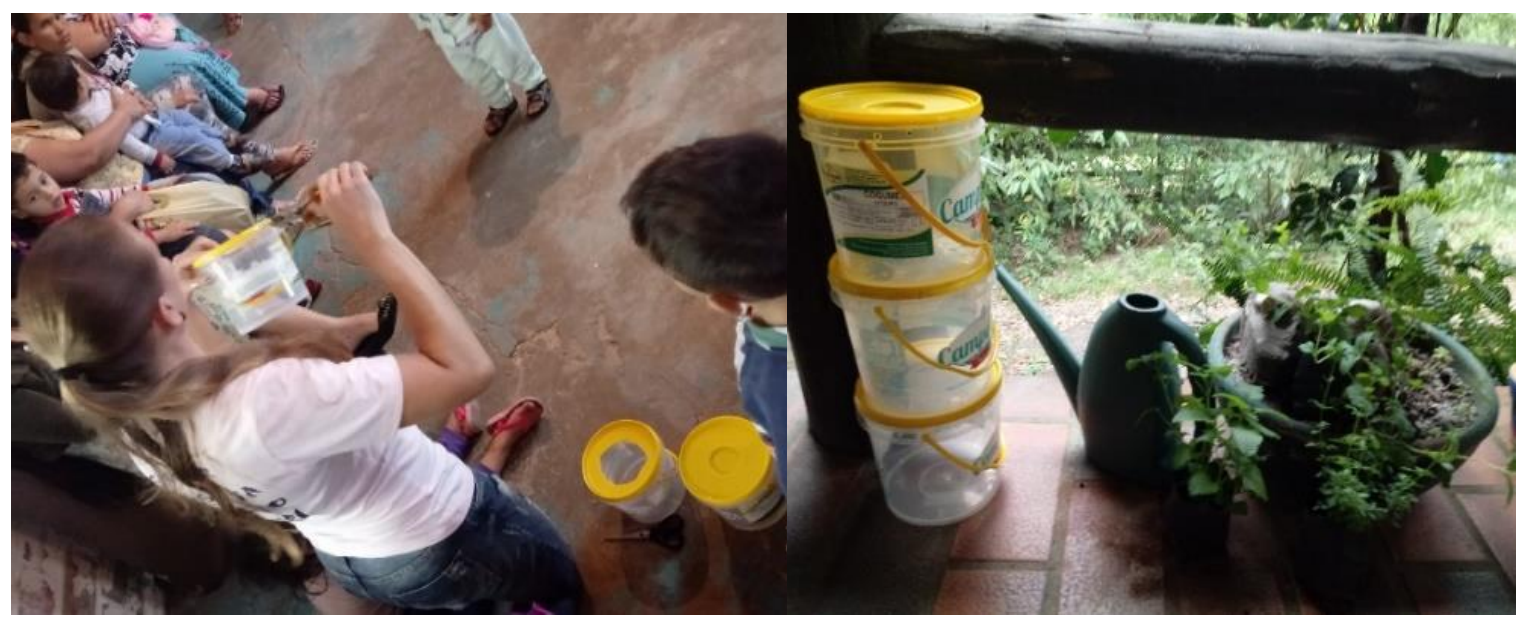

Fonte: Arquivo pessoal da autora.

A confecção das composteiras mostra ainda a possibilidade do reaproveitamento de materiais que poderiam ser descartados nas residências, como baldes, bacias, tijolos e outros materiais de construção na produção de equipamentos úteis à produção de alimentos nos domicílios e espaços públicos. Assim, é visível que não apenas o composto orgânico pode ser 
reaproveitado em forma de compostagem a fim de melhor nutrir o solo, mas também diferentes materiais podem ser somados a ideia de produções que sejam ambientalmente sustentáveis. Além disso, o processo de construção das composteiras domésticas possibilita um trabalho de desenvolvimento da habilidade criativa dos familiares e, como destacado na figura 2, também auxilia no desenvolvimento da psicomotricidade das crianças que nesta tarefa se envolvem, propiciando ainda um espaço de convivência colaborativa entre adultos, jovens e crianças.

\section{Referencial Teórico}

Existem diversas correntes e compreensões de Educação Ambiental e cada uma expressa uma maneira diferenciada, cada uma delas, dentro do que se propõe, tenta realizar o que considera correto.

O que, de fato, seria Educação Ambiental? Guimarães (2004) em seu texto, apresentanos uma maneira nova de organização do nosso pensamento, onde a re-conceituação não significa apenas conceituar algo com outras palavras. A reconceituação, no caso da Educação Ambiental não é o simples acréscimo de novas ideias mas “[...], é uma contraposição a algo existente, como forma de superação (GUIMARÃES, 2004, p.25)".

Mauro Guimarães, que tomou como referência para sua formação o pensamento de Milton Santos, Paulo Freire e Edgar Morin, compreende que:

A Educação Ambiental Crítica objetiva promover ambientes educativos de mobilização desses processos de intervenção sobre a realidade e seus problemas socioambientais, para que possamos nestes ambientes superar as armadilhas paradigmáticas e propiciar um processo educativo, em que nesse exercício, estejamos, educandos e educadores, nos formando e contribuindo, pelo exercício de uma cidadania ativa, na transformação da grave crise socioambiental que vivenciamos todos. (GUIMARÃES, 2004, p.30)

Assim, é possível afirmar que Educação Ambiental Crítica, baseia-se em projetos que podem ir além das salas de aula. Estes projetos visam a problematização do meio ambiente que nos cerca em busca de soluções viáveis. A proposta da Educação Ambiental crítica é não individualizar as formas de vida, mas sim, trazer o entendimento de que sem a interação dos seres vivos, o planeta não sobreviverá.

Segundo Loureiro (2004) a prática da Educação Ambiental, não deve ser vista como uma simples abordagem de passar conhecimentos, mas sim, como uma maneira de focar o 
cidadão nos assuntos relacionados ao ambiente, buscando alternativas reais, soluções inteligentes e cabíveis de problemas, sempre lembrando que fazemos parte deste ambiente, que dele necessitamos. Devemos formar cidadãos críticos, com percepções futuras e que consigam tornarem-se multiplicadores destas idealizações.

Em sua obra, Trajetórias e Fundamentos da Educação Ambiental, Loureiro (2004), nos propõe um resgate dos conceitos e das estruturas pedagógicas críticas da Educação Ambiental, buscando esclarecê-las, visando o resgate e a transformação da existência. A consciência ambiental e fundamental para os dias de hoje, para termos maneiras de vivermos de maneira sustentável.

Uma pesquisa realizada pelo Ministério do Meio Ambiente (MMA) demonstra que a conscientização ambiental brasileira aumentou em 30\% nos últimos 15 anos. Infelizmente, esta mesma pesquisa traz os dados sobre a falta de ações sustentáveis individuais e coletivas no dia a dia. De que adianta termos boas intenções se estas não são praticadas?

As ações realizadas com esta comunidade vem ao encontro do que a Educação Ambiental crítica nos propõe. A pretensão foi fazer com que estas mulheres, tornem-se multiplicadoras de conhecimento desenvolvidos dentro da sua comunidade. Também foi intuito da ação que a confecção e utilização das composteiras - com a consequente produção dos alimentos, através de hortas - pudessem permanecer dentro da comunidade, para que aqueles que nela vivem consigam fazer uso de suas benfeitorias. Ao mesmo tempo será possível contribuírem com o ambiente em que vivem, entendendo que dele fazem parte e que há uma real necessidade deste zelo.

\section{Análise das Informações}

É possível trabalhar Educação Ambiental Crítica, a partir de uma composteira?

Trabalhar com a temática da Educação Ambiental em um sábado à tarde para um grupo de mulheres que talvez não gostariam de estar fazendo isso naquele momento, foi um desafio. Primeiramente havia o convencimento, de que aquilo que estava sendo apresentado era verdadeiramente importante. Depois, que uma mudança de hábito por parte delas, poderia ser realmente eficaz em termos de contribuição para o ambiente.

O questionário aplicado, com o intuito de sondagem, relacionou as seguintes questões: 
- Você sabe a diferença entre resíduo orgânico e seco?

- Se sim, faz separação seletiva dos seus resíduos?

- Se não, porque razão não faz a separação de resíduos?

- Você tem ou gostaria de ter uma horta em sua residência?

- Tem conhecimento que existe recolhimento seletivo em sua cidade?

- Conhece as vantagens da compostagem doméstica?

- Você tem interesse em construir uma composteira (baixo custo) em sua residência?

Dez mulheres responderam ao questionário, oito delas disseram saber a diferença entre resíduo orgânico e seco; nove delas não realizam separação dos resíduos, destas quatro responderam que não sabiam como era realizada, três responderam que nunca foram sensibilizadas para esta ação; duas declararam não ter interesse pelo destino de seu lixo e uma relatou não ter tempo para a realização da separação de resíduos.

Mediante aos resultados, sentimos necessidade da realização de uma palestra para desenvolver algumas ideias iniciais sobre a Educação Ambiental, uma mini oficina de separação dos resíduos secos e orgânicos e de uma composteira. Na palestra, foram expostas as diferenças entre os resíduos secos, orgânicos e aqueles que necessitam descarte especial, como lâmpadas e pilhas. Para os descartes especiais foram indicados locais que realizam a coleta deste tipo de resíduo no município. Na oficina, os participantes puderam manusear e classificar os resíduos secos, como papel e plástico, por exemplo. O resíduo orgânico havia sido previamente separado, durante uma semana, para ser mostrado durante a oficina.

A partir da primeira ação, da exposição teórica e prática sobre o assunto, o interesse foi surgindo. Conseguimos desenvolver associações com o cotidiano, onde ações realizadas por elas que poderiam ser modificadas por uma mudança de hábito, como por exemplo um descarte correto de resíduo seco ou orgânico, um lixo descartado no chão e as consequências que tais hábitos podem acarretar.

Percebemos que as participantes compreenderam que os descartes em lugares inapropriados podem trazer diversas consequências ao ambiente e aos seres que nele vivem. Matéria orgânica em decomposição pode atrair animais indesejados, inclusive algumas enfermidades foram citadas pelo mau descarte deste tipo de resíduo.

Durante a segunda ação, já pode ser observada por elas, a importância da separação e do descarte correto dos resíduos. Foi discutido que os resíduos secos poderiam ser 
reaproveitados e, no caso dos orgânicos, poderiam reverter adubo para ser utilizado em hortas e jardins.

A partir das ações, percebemos que o projeto desenvolvido vai ao encontro do que diz Loureiro (2004, p.36) “[...] devemos formar cidadãos críticos, com percepções futuras e que consigam ser multiplicadores destas idealizações." As mulheres participantes, tornaram-se multiplicadoras deste conhecimento, junto as suas famílias. Servem de exemplos a serem seguidos, levando aquilo que aprenderam para aqueles que estão em seu entorno.

\section{Considerações}

Na realização desse trabalho ficou evidenciada na comunidade, do bairro Aurora, a situação de distanciamento das boas práticas ecológicas, sejam elas motivadas pela simples desinformação, pela falta de estruturas e serviços que deveriam ser oportunizadas pelo poder público e também por uma certa "inércia". Comum a comunidades que vivem em áreas precárias (e frequentemente sem perspectivas de melhorias em curto e médio prazo), em que, movidas pelo desânimo, as pessoas tendem a considerar normais situações que na verdade são inaceitáveis, tais como a deposição de lixo (e suas consequências) junto às moradias e a transformação de cursos hídricos em esgotos fétidos à céu aberto.

A prática de descartar o resíduo de maneira correta, a separação do lixo, não acontece em grande parte das comunidades. Uma parcela grande da população vive, com o pensamento, de que podem, e devem tirar proveito dos recursos que o ambiente oferece, sem pensar nas consequências a curto e longo prazo que estas ações podem ocasionar.

Este projeto visou desenvolver com a comunidade do bairro Aurora, conhecimentos sobre uma maneira de reciclar o material orgânico, fazendo com este volte para a natureza sem causar malefícios. Um projeto de Educação Ambiental com baixo custo e de grande valia para aquela comunidade carente, que além de ser orientada a produzir seu adubo, também pode perceber vantagens na correta separação do material seco, que este pode vir a contribuir ao orçamento doméstico. Promovendo o desenvolvimento sócio econômico e sustentável, para aqueles que quiserem aderir à proposta, trazendo possíveis melhoras financeiras para os envolvidos e significativas mudanças para a melhoria ambiental no bairro onde vivem.

A intenção é que este projeto continue. Assim que o composto produzido esteja pronto para uso, o novo projeto será o desenvolvimento de uma horta comunitária, no mesmo local onde já havia uma há alguns anos atrás. 


\section{Referências}

FONSECA, V. M da. A educação ambiental na escola pública: entrelaçando saberes, unificando conteúdos. São Paulo: Biblioteca 24X7, 2009. 228p.

GUIMARÃES, M. Educação Ambiental Crítica In: Identidades da educação ambiental brasileira / Ministério do Meio Ambiente. Diretoria de Educação Ambiental, Brasília, 2004 p.25-34

LOUREIRO, C. F. B. Trajetórias e Fundamentos da Educação Ambiental. São Paulo: Cortez, 2004.

MASSUKADO, L. M. Desenvolvimento do processo de compostagem em unidade descentralizada e proposta de software livre para o gerenciamento municipal dos resíduos sólidos domiciliares. 2008. 182p. Tese (Doutorado). Escola de Engenharia de São Carlos, Universidade de São Paulo, São Carlos, 2008.

MOREIRA SÁ, E. V. Validação de um modelo de compostagem usando um compositor doméstico. Dissertação de Mestrado em Engenharia do ambiente. Universidade de Aveiro, Portugal, 2009.

OLIVEIRA, A. M. G; AQUINO, Adriana Maria de.; NETO, Manoel Teixeira de Castro. Compostagem caseira de lixo orgânico doméstico. Cruz das Almas - BA, 2005. Circular Técnica. Empresa Brasileira de Pesquisa Agropecuária - EMBRAPA.

WANGEN, D. R. B.; FREITAS, I. C. V. Compostagem Doméstica: alternativa de aproveitamento de resíduos sólidos orgânicos. Revista Brasileira de Agroecologia. v. 5, n. 2, páginas 81-88, 2010.

MONTEIRO, J.A. V.. Benefícios da compostagem doméstica de resíduos orgânicos. Revista Educação Ambiental em Ação. N.56, ano XV, Junho-Agosto, 2016. 